\title{
Reflections on the Nature of Public Ethics
}

\author{
JONATHAN MONTGOMERY
}

\section{Introduction}

This article explores the differences between the activities of ethical deliberation in the academy and in the public domain, in particular in the work of bodies appointed to advise government. ${ }^{1}$ It draws attention to the collegiate nature of their work, the constraints imposed by their constitution, and the need to incorporate attention to the sociopolitical context. It argues that such "public ethics" is fundamentally a contingent process, driven by pragmatic arguments rooted in particular times and places. If this is correct, the work of advisory bodies should be assessed on a different basis from academic papers and should be regarded more as historical documents than works of principle. The nature of the "expertise" that should be brought to bear and some related questions about the concept of evidence-based policymaking are also considered. ${ }^{2}$

When asked, in 2008, to advise on the introduction of a system of presumed consent or an opt-out system, the UK Organ Donation Taskforce (ODT), a multidisciplinary group charged with improving donation rates, concluded that such a system should not be introduced at that time. ${ }^{3}$ The main reasons given were as follows:

- It might undermine the idea of donation as a gift, erode trust in NHS professionals, and even reduce donation numbers.

- It would distract attention from improvements in infrastructure for donation, retrieval, and transplantation and also from activity to promote public understanding.

- It would be challenging and costly to implement. ${ }^{4}$

The first group of claims is essentially empirical and in principle is subject to testing-the ODT commissioned a literature review of the available evidence. ${ }^{5}$ The second group of claims is heavily contingent on the specific policy context in which the ODT was working. The taskforce had already completed a first report that focused on structural changes, and these were being implemented. ${ }^{6}$ The changes were the responsibility of individuals whose time was limited and needed to be prioritized. This could be seen as an issue of opportunity costs; that is, it is less about the benefits of reform than about the inability to pursue other

I am grateful to colleagues in the Health Ethics and Law Network at the University of Southampton and to the participants in the workshop "Organ Donation and Consent" held at Keele University in December 2010 for their comments and advice on earlier versions of this article. I am particularly grateful to Sheelagh McGuinness for helping disentangle some confusions. The errors that remain are entirely my own responsibility. 
policies that might be more important at that particular time. The conclusions reached by the taskforce need to be appraised in the light of this context. It is one of the contentions of this article that any analysis that ignores specific historical context cannot provide an adequate critique of the work of commissions set up to undertake public ethics. Some features of the third group of claims overlap with this point. However, their essence is not lost opportunities but rather the social, political, and economic costs of implementation of an opt-out policy. These challenges, although varied in nature, are all contingent on the context within which the recommendations were addressed. It is necessary to consider how a move to presumed consent would resonate with wider political currents of the time in order to determine whether the taskforce's conclusions were sound. This raises some interesting questions about the connection between public opinion and policymaking, and the taskforce's rejection of presumed consent despite apparent support from the public can be said to be counterintuitive. ${ }^{7}$ This sociopolitical context also requires consideration of the role of the media and politicians.

The arguments raised by the taskforce's report had a different emphasis from many of the more traditional ethical analyses of this area, although the latter were considered by the Ethics Working Group. ${ }^{8}$ It is also interesting that the language of presumed consent was replaced with that of opting out in the main report. The terms of reference for the taskforce's work- "to examine the potential impact on organ donation of introducing an opt-out or presumed consent system across the UK, having regard to the views of the public and stakeholders on the clinical, ethical, legal and societal issues" ${ }^{\prime 9}$-wrapped these concepts up together. However, the issues raised are rather different. The basis of an opt-out system is not that people in fact consent (the implicit logic of the chief medical officer) ${ }^{9}$ but that it may be legitimate to take organs irrespective of consent. This is an issue that raises questions about the nature of our stakes in our bodies, including whether that nature can be captured through a concept of ownership.

These latter types of arguments have been subject to much discussion by bioethicists but were not the driving concern of the taskforce. This article reflects on aspects of the nature of public ethics that lead to this divergence between the concerns of academic commentators and the work of public advisory bodies.

\section{Some Features of Doing Public Ethics}

There are at least four aspects of doing public ethics that lead to constraints to which individuals are not usually subject. The first is that public ethics is usually done by groups of people commissioned to explore the issue and make recommendations. They are not free to simply adopt a personal perspective, although there is scope for minority reports. They are not in a position to choose the colleagues with whom they collaborate, and they need to work with the other members of the group. Furthermore, the scope for defining the questions they ask is limited by the terms of their commission. The second aspect is the prevailing policy context, which makes some solutions more feasible than others. This is partly a matter of pragmatism - what can be achieved with the tools realistically expected to be available (the healthcare system, scientific possibilities, likely resource context, etc.). It is also important to recognize that public ethics is a political enterprise that needs to take into account the art of the possible as well as the logical force of the arguments being put forward. This extends into the 
third category, which concerns questions about discourses of legitimation. In academic writings, originality of approach is often commended, but in the more public context, it may be a disadvantage. Public ethics is an art of persuasion as well as of logic. Sometimes the best logical arguments may not be the most convincing for the audiences to which they are addressed. The final category concerns the impact of the media and public opinion on the thinking of those appointed to examine the issues. Intriguingly, the ODT was asked in its terms of reference to have "regard to the views of the public and stakeholders on the clinical, ethical, legal and societal issues." This is subtly different from addressing those issues independently and also from accepting public opinion as the basis of policy.

\section{The Collegiate Nature of the Enterprise}

Although academics can work collaboratively, the norm in bioethics is for individuals to present the arguments as they see them personally. This is not the case for the members of committees set up to give advice to governments or the public. Instead, the formulation of views that can be agreed on by the group is a collegiate process. ${ }^{10}$ This leads to a situation whereby members need to decide whether the conclusions reached, the arguments for them, and the terms in which they are formulated are ones that they can accept, even when they would not have reached or articulated them in the same way. This can present particular challenges for individuals who have previously publicly expressed a different position.

This cluster of issues can be illustrated by the recommendation of the Warnock Committee that research on human embryos should be permitted for up to fourteen days (subject to regulatory approval). ${ }^{11}$ No clear rationale for this recommendation was set out in the report, but it was based on a number of factors: correspondence with the point at which implantation in the wall of the uterus was likely to occur, emergence of the "primitive streak" (which develops into the nervous system), and individuation. These positions hint at rationales based on consistency with abortion law (the legality of the morning-after pill is based on the fact that the Offence Against the Person Act 1861 criminalizes procuring a miscarriage-that is, when implantation has occurred), ${ }^{12}$ utilitarianism (no pain can be felt without a nervous system), and arguments for genetic uniqueness providing the basis for human personhood. ${ }^{13}$

The important point here is that the Committee adopted two crucial positions that reflect the public nature of its task and represent characteristic constraints on work in public ethics. First, the committee concluded that there needed to be a precise line if the proposed laws were to be workable, hence the adoption of a specific number of days. This is a concern common to many legal interventions, in which a "bright line" is thought to be required. ${ }^{14}$ The second concerned the nature of the compromises involved. Mary Warnock has suggested that, to succeed, the recommendations had to be seen

not as perfect, but as reasonable and not unduly offensive to people's moral feelings. We had to hope, that is to say, to achieve a broad consensus about what could be tolerated, even by those who would have preferred prohibition to regulation.

I learned that the language of "right" and "wrong" was inflammatory; that it sounded arrogant, and that it provoked conflict. The very best one 
could hope for was to find something roughly "acceptable." ... Our task had been to recommend a policy that might allow the sort of medical and scientific progress which was in the public interest, while at the same time not riding roughshod over the moral scruples of a significant number of the public. ${ }^{15}$

Public ethics thus aspires more to acceptability than to philosophical neatness. The members of committees can adopt conclusions for a variety of reasons, which may be mutually inconsistent, provided they give a basis from which policy can be developed.

This characteristic should be familiar to those who adopt principlist approaches to medical ethics, based on the idea that the principles (like autonomy, beneficence, etc.) can be adopted for different philosophical reasons but provide a common currency for the resolution of practical problems. ${ }^{16}$ It is also familiar to lawyers who address the mythology of Parliamentary intention; only very limited attention can be paid to the reasons why legislation was passed, the focus being on the words that were agreed on.

\section{Assessing the Context}

Another aspect of doing public ethics is that the appointed bodies are working in a specific time, place, and policy context. This section focuses on the implications of resource constraints. The ODT was initially established to examine not ethical and social issues but rather practical measures for improving transplant services in the context of the National Health Service, a system of socialized medicine. Its presumed consent work was done at a time when a program of reform of the organ retrieval system had just been put into place, and relevant clinical leaders were already engaged in its implementation.

This has a number of significant implications. First, relevant people were a scarce resource and could not simultaneously implement the organ retrieval reforms and engage in a public debate. Thus, a judgment was needed on the relative priority of system reform and legal change in increasing transplantation rates. This was partly an issue about logistics. It was also an exercise in changing the service culture. If the program were to be successful, staff needed to have a positive attitude to donation. The program was intended to improve the effectiveness of donation, retrieval, and transplantation procedures and was quite independent of the work on changing the consent system. However, there was a connection. Presumed consent relies for its success on clinical staff being willing to take organs on the basis of such a presumption. If not, they might continue in practice to operate an opt-in system because of their concern about the ethics of consent.

The conclusion of the ODT, that the case for a presumed consent or opt-out system was not convincing, needs to be judged in this very specific historical, organizational context. Hence the committee recommended that reform should not occur in 2008 and that issues should be reviewed after five years if organ donation and transplantation rates had not improved. From the perspective of those who are interested in the moral legitimacy of presuming consent to donation, or the strength of the imperative to assist those in need of transplant organs, this "not now, not yet" conclusion might seem to lack courage. However, as a pragmatic decision about how to improve transplant rates in a specific, resource-constrained context, it is more easily explicable. 


\section{Sowing on Fertile Ground?}

Public ethics requires a sophisticated exploration of the receptiveness of the audiences that are being addressed. Writers in the academy can play a "long game," challenging orthodoxies and assumptions in the confidence that once their work makes it into the journals, it can lie dormant until people are ready to appreciate the importance of the insights being offered. It is not necessary for the audience to accept the arguments or frameworks being put forward; it is merely necessary for the peer reviewers to recognize them as sufficiently novel and interesting to publish. Public ethics can be addressed to a wide range of audiences, including experts, advisers, service providers, governments, the media, and the general population. However, there is normally a relatively narrow window of opportunity to speak to these audiences, and that opportunity arises in a particular social, political context at a specific point in time.

Understanding the discourse of public ethics therefore requires greater attention to the context than is generally seen in academic literature. This point can be illustrated by two aspects of the report Public Health: Ethical Issues produced by the Nuffield Council on Bioethics (NCB) in 2007: ${ }^{17}$ first, the adoption of a broadly Millian framework of analysis in the conceptual chapters of the report and, second, the use of the label "stewardship model" to characterize the approach being proposed. In both cases, the academic literature has raised interesting questions about the suitability of the stances taken that provide fertile lines of inquiry. However, the debates that they engender obscure one of the dimensions of the decision made by the working party to use that framework.

The adoption of the Millian framework was attractive because of its fit with the prevailing public political discourse's antagonism to the "folk devil" of the "Nanny State." Mill's harm principle captured the populist rejection of the idea that the state should dictate to people how they should look after themselves. It was also attractive because of its familiarity to the terms of public debate. ${ }^{18}$ It enabled the explanation in noncontroversial terms of the legitimacy of a number of activities that public health ethics was thought to support, like quarantining of infectious patients. It therefore seemed a reasonable starting point to win over the sympathies of key audiences and to enable exploration of the more controversial or difficult areas to which the working party sought to draw attention.

From the perspective of academic analysis, it is interesting to explore whether greater explanatory power can be found in other frameworks (as suggested by John Coggon's critique in the Journal of Medical Ethics). ${ }^{19}$ However, such a foundation would lose the communicative power that comes from building on and exploiting a familiar thinker known to the intended audiences. Coggon also makes interesting points about whether or not the working party needed to supplement the Millian framework so as to create a "revised" liberal framework. He suggests that the richness of Mill's essay On Liberty ${ }^{20}$ is such that the additional factors could have been justified by a broader reading of the text. However, if public ethics is an exercise in persuasion, it is important to ensure that the audience appreciates the difference between the proposals that are being made and their expectations of the thinker on whose work we are drawing. It was, therefore, reasonable for the working party to proceed on the basis that, for the main audience, On Liberty had become synonymous with Mill's famous 
harm principle and that the wider nuances of his argument were unfamiliar to them-most would not have actually read the essay but instead would have absorbed it indirectly. Thus, it is easier to defend both the presentation of the report as an extension of Mill's approach rather than a rereading of the essay and also the adoption of the harm principle as a starting point, if they are seen as exercises in public communication rather than arguments addressed to colleagues in the academic communities. The strategy makes clearer sense as public ethics than as an exercise in philosophy.

\section{Public Reception}

A related but somewhat different point can be made about the adoption of the term "stewardship." Such a label is necessary to facilitate debate in a media context that favors dramatic images and sound bites over subtle and protracted arguments. Thus, for public ethics some rhetorical tools are needed to improve the impact of the work, a shorthand slogan to aid communication through the media. For academic commentary, such simplifications come across as simplistic. ${ }^{21}$ The selection of the stewardship tag was a decision taken at a relatively late stage in the deliberations of the working group and looked attractive in part because it provided an association with two influential organizations: the World Health Organization, through a minor comment made in passing, ${ }^{22}$ and the King's Fund, in the title of a report on government responsibilities in public health. ${ }^{23}$ The stewardship label therefore served to imply that the proposals were not entirely alien and had some roots in existing thinking by one of the communities (health policymakers) that the report sought to influence. Although insignificant in relation to wider public acceptability, this might assist in the report's reception into some of the key professional groups to whom it was addressed.

Thus, in different ways, the use of John Stuart Mill's famous harm principle and the epithet of stewardship are accommodations into the thinking of the working party of the implications of exploring ethics in a public sphere rather than within the academy. It is entirely right for academic work to draw attention to the shortcomings of pronouncements in order to test and refine them. However, it is also appropriate to note that the context of public communication introduces different aspects to the challenge of doing ethics. Public ethics needs to pay more attention to the way in which its contribution will be understood than it does to writing for academic colleagues, not least because the audience does not share the same technical vocabulary or canons of interpretation that the community of scholars has developed.

Similar issues about the public reception of proposals are evident in the work of the ODT, but with an additional interesting dimension. Here, the political context in which the problem was being explored was important. Although the work on presumed consent had been prompted by the annual report of the chief medical officer, the reform had also received the personal endorsement of the prime minister, Gordon Brown, writing in the Sunday Telegraph: "A system of this kind seems to have the potential to close the aching gap between the potential benefits of transplant surgery in the UK and the limits imposed by our current system of consent." ${ }^{\prime 24}$ Such senior personal sponsorship cast a shadow over the taskforce's apparently neutral commission to enquire into the issues by suggesting the answer that was hoped for. In so far as concern is given to the likely government response to recommendations, there was a pretty explicit indication of what was expected. 
Even more interesting was the wider shadow cast by Gordon Brown's support and the way in which some sections of the media were able to present the issues as linked with more general political debates. In his Telegraph blog, Gerald Warner wrote: "Gordon Brown has appropriated just about everything we own, so it is no surprise that he is now trying to nationalise our bodies. . . . Presumed consent would be the ultimate victory of the New Labour totalitarians: the acknowledgement that they own us down to the last sinew and tissue. It must be rejected." ${ }^{25}$ Minette Marrin offered a neat turn of phrase in the Sunday Times, under the headline "Even in Death Our Organs Are Not for the PM to Snatch": "The idea lets in an evil and dangerous political principle-the assumption that the state owns our bodies. Brown and Labour governments before him have tried to nationalise our private lives; now he wants to nationalise our private parts." 26

Academic explorations of the property analogy are rooted in argument, but in the domain of public ethics they need also take into account the personal and party political context, which as these interventions show is pretty rough. Those charged with developing positions on public ethics need to take political context into account. This may mean that some arguments that are persuasive in the abstract become dangerously vulnerable at particular times and in particular places because of political factors that are only loosely connected with the issue in question.

\section{Some Problems in Public Ethics}

These characteristics of public ethics require an acknowledgement of the peculiarities of the contexts in which the enterprise is undertaken. There are also some very specific challenges in working on public policy in relation to bioethics that deserve consideration and on which academics (from a wide range of disciplines) have a considerable contribution to make in elucidating the issues and proposing solutions to the dilemmas raised. They have, however, not yet received the attention that they deserve. Three of these challenges will be raised here: the handling of disputes over science, the weight to be given to public opinion, and the use of international comparisons. In different ways these can displace the careful ground rules of academic argument with the raw power of politics. If public ethics is to be done well, it needs to develop an account of how arguments should be tested and validated in light of these types of pressures.

\section{The Nature of Evidence}

There are particular difficulties when the public clashes with the scientific community on matters of safety. How should public ethics address assertions that measures advocated by professionals are unsafe? One solution lies in the mantra of evidence-based policymaking. However, views of what counts as evidence may vary between "experts" and the politicians, policymakers, and public to whom recommendations are addressed. This was a significant issue for the NCB Working Party on Public Health Ethics. It came up in two specific contexts in which public and expert perceptions of the evidence differed-vaccine safety and fluoridation of water supplies. Although these raise very different issues-and were hence treated in separate case studies in the report-they overlapped in raising the problem of contested evidence on issues of safety and efficacy and how this controversy should be taken into account. 
In relation to the former, the working party reflected on the controversy around the MMR vaccine, that is, when public confidence declined following the publication of a research paper in the Lancet and was not restored despite the later statement by the journal that the paper was flawed and despite retractions by most of its authors relating to some of the conclusions. The working party concluded that media reporting "can influence public perceptions, potentially hindering public health measures and affecting population health." ${ }^{27}$ It considered that the responsible communication of scientific findings was a duty of researchers and journalists and that it should take into account professional guidelines on science and health communication. Implicit in this approach is a commitment to privileging expert views on what counts as evidence over public opinion. ${ }^{28}$

There is, of course, much to be debated about evidence-based policymaking. Evidence does not become available by accident. There may be both research commissioning and research publication biases, but an absence of evidence may look like evidence of absence of an effect. Nevertheless, in the sphere of public ethics, it seems reasonable for policymakers to take into account the mechanisms that government has put into place to assess scientific evidence and to accept the position of these mechanisms on controversial issues. Thus, in relation to the safety of vaccines, public ethics might properly rely on the advice of the Joint Committee on Vaccination and Immunisation and of the Medicines and Healthcare Products Regulatory Authority. This will frequently bring the findings of groups charged with doing public ethics into conflict with some sections of the public. ${ }^{29}$

A solution may lie in separating fact questions from value judgments, that is, seeing the former as amenable to expert decisionmaking (for which institutions can be created) and the latter as amenable to politics. The ODT's approach to the public support for reform might be seen to be an example of this (see subsequent further discussion). It suggested that public support for an opt-out system was based on a dominant desire to improve donation rates and that therefore the implementation of the system should be conditional on it delivering this. It took the commitment to more transplants as a reliable piece of data but the belief that opt-out would lead to this as a hypothesis to be independently tested.

This difficulty of disentangling fact and value questions can also be seen in the NCB working party's discussions of fluoridation of water supplies, another area of significant public concern over safety. ${ }^{30}$ The report noted that the expert consensus was that the "best available evidence" is that water fluoridation is effective and that there is no clear association between fluoridation and bone problems or cancers (the most significant harms identified by those opposed). ${ }^{31}$ These would appear to be problems that concern interpretation of scientific evidence. There is an established dose-response relationship between fluoridation and fluorosis, but here the divergence of views is more value based. This can be seen within the scientific studies themselves, in the use of a measure based on fluorosis "of aesthetic concern" to assess whether there are health problems. Aesthetics is a matter of a different kind of judgment, on which it is less obvious that the expertise of scientists should be privileged over that of the public.

The problems of how to take account of public views on matters of scientific fact have recently been aired in an English judicial review case challenging NHS (National Health Service) South Central's decision requiring fluoridation of water. $^{32}$ Before making its decision, a health authority is obliged to consult and ascertain public opinion and "shall not proceed . . . unless, having regard to the 
extent of support for the proposal and the cogency of the arguments advanced, the Authority are satisfied that the health arguments in favour of proceeding with the proposal outweigh all arguments against proceeding. ${ }^{\prime 33}$ The majority of the public who responded to the consultation was opposed, as were four of the five relevant local authorities. ${ }^{34}$ However, the authority could consider the "cogency" of the scientific arguments raised, and it found them unconvincing. The court held that the Authority's decision to proceed despite public opposition was not unlawful. This approach suggests that where matters of scientific evidence are concerned, public opinion is not determinative. Indeed, as the court noted, the draft regulations on fluoridation had suggested that fluoridation should not happen unless local people and representative bodies were "predominantly in support" of it. However, this was replaced by the final wording after discussion as to the undesirability of holding a local referendum. This has made issues of efficacy and safety a matter for expert evidence rather than public confidence.

This distinction between factual evidence (which is to be tested against the "truth conditions" developed by experts and based on peer review) and value judgments (to which public opinion has a more significant contribution to make) is not always easy to make and brings its own problems. However, it may provide a workable tool for structuring public ethics. If so, it deserves more extensive consideration than can be offered here, but instead I want to illustrate some difficulties relating to the value judgment side of the distinction. Public ethics is not merely a matter of public opinion. If it were, then these value questions could be turned into questions of evidence to be resolved by polling. Some of the challenges of this can be seen in the work of the ODT on presumed consent.

\section{Public Opinion and Public Policy}

As has already been noted, the taskforce was asked to carry out its work "having regard to the views of the public." It sponsored a series of deliberative events in which more than 350 members of the public were able to explore the issues with experts. ${ }^{35}$ Initially, 65 percent were supportive or strongly supportive of the move to an opt-out system, whereas 26 percent were opposed or strongly opposed. After their deliberations, the proportions shifted slightly, to 72 percent and 23 percent. $^{36}$

The taskforce observed that

participants assumed that introducing an opt out system would increase organ donor numbers.... Indeed, some participants considered that they would not have been assembled for such an exercise if this had not been the case. Many participants felt that only people with strong convictions would be likely to opt out, which would mean that the majority of people would be registered as donors. ${ }^{37}$

It concluded that the public expression of support was based on the hypothesis that an opt-out system would lead to more donations. From this it was inferred that the best analysis of the position was that the public supported the legal reform if it increased donor numbers (or perhaps more precisely, it was inferred that the public supported it because they believed it would increase donations and that if that belief turned out to be false, then their support would be withdrawn). Once the taskforce concluded that the hypothesis was false, then it was also in 
a position to disregard the expressed public support as being based on a false premise.

At first glance, this approach may appear perverse, in that it takes note of public opinion only to reach precisely the opposite opinion from the one expressed. However, it should not be dismissed too lightly. "Public opinion" is routinely used by campaigners to support their causes, even when they have diametrically opposed views. Thus, the members of Dignity in Dying point out that the British Social Attitudes Survey in 2010 showed that 82 percent of the general public "believe that a doctor should probably or definitely be allowed to end the life of a patient with a painful incurable disease at the patient's request." ${ }^{38}$ From a very different policy position, the members of Care Not Killing also rely on public opinion to resist the legalization of euthanasia, drawing from an opinion poll in 2006 that found that 75 percent of people agreed that "people with treatable illness such as depression might opt prematurely for suicide." ${ }^{\prime 39}$

The taskforce acted reasonably in seeking to understand what lay behind public views. Much more needs to be said, however, about the weight to be put on public opinion and precisely how it should be taken into account in policymaking. Philosophical traditions that explore the relationship between common morality and ethics can bring significant expertise to this exercise. ${ }^{40}$ However, this was not the approach taken by the taskforce, which instead turned to testing the hypothesis on which it found public opinion to be based. It did this by drawing on what could be learned from international experience, and in taking this step it needed to address a further familiar challenge in public ethics.

\section{Making Comparisons Meaningful}

It is quite common in public ethics, and indeed in academic literature, to use international comparisons as a basis for policy proposals. The ODT drew on the experience of Texas as evidence that mandated choice might lead to a reduction in donations (when forced to choose, people preferred to say no, even when they might have been happy to leave things open or say less without the presence of coercion). ${ }^{41}$ This is an entirely acceptable observation provided that little is predicated on the "might." In reality, however, the might observation was used as an argument and implied sufficient probability to constitute a reason for not proceeding down that route. That involves a much more complex claim about the translation of the conclusions from the Texan study to a different sociopolitical context. It relies to an implausible degree on the independence of human nature from social environment.

Similar points can be made about the appropriateness of drawing inferences from associations. An association between presumed consent regimes and higher donation rates can be seen in both international comparisons and before-andafter studies that looked at rates prior to the introduction of presumed consent regimes and what happened once they were in place. However, the ODT noted that there were significant confounding variables and that presumed consent alone was unlikely to explain the variations. ${ }^{42}$ It used this to downplay the significance of this evidence for the formulation of policy. Nevertheless, the taskforce members did put considerable weight on the Spanish experience, which they argued demonstrated that presumed consent worked only in tandem with an efficient infrastructure. They noted that the introduction of the presumed 
consent legislation predated the increase in the donation rate, which followed the system reforms, not the legal ones. This led them to their prioritization of the implementation of their first report over a new program for law reform.

Work needs to be done on the principles that should govern the use of such examples. Comparative analysis is seductive; one is drawn to make use of overseas experiences where they seem to confirm one's position and to distinguish those areas where they do not. The systematic literature review that the taskforce commissioned drew on the principles of meta-analysis developed by evidence-based medicine. ${ }^{43}$ One could conclude from this that there are so many variables that the idea that solutions can readily be transplanted is confounded. However, despite this, international examples are often used in public ethics as if they were reliable guides to the consequences of reform. The ODT saw the complexity of this but could be accused of using such evidence (despite its difficulties) when it suited the policy being proposed and resisting it when it did not. It remains unclear how to make the most effective use of comparative analysis in good public ethics.

\section{Conclusion}

This article has tried to show that engaging in public ethics has a different set of ground rules than making a personal contribution to academic literature. If this is true, then a personal exploration of the case for an opt-out system for organ donation would be very different from the analysis offered here. My personal view is that a conscription model for organ retrieval can be defended. I would not, however, offer such an argument as an exercise in public ethics as described in the body of this article. It would be too far removed from the accepted currency of that enterprise, insufficiently plausible in the prevailing political discourse, and too open to ridicule in key sections of the media to be likely to lead at this time to the type of society in which I would like to live. Instead, I am content to have been part of the work of the ODT discussed previously. Public ethics can be a significant contribution to shaping a more attractive society, but it is not the same as working in the academy. It has its own rules of engagement that will not be acceptable to everyone but that are a suitable area of study in their own right.

\section{Notes}

1. The article draws on the author's experience of sitting on the Organ Donation Taskforce, the working party of the Nuffield Council on Bioethics (an independent UK body that produces reports on ethical issues in biology and medicine) that produced its report entitled Public Health: Ethical Issues, and the UK health departments' Committee on Ethical Aspects of Pandemic Influenza, and of chairing the Human Genetics Commission. It sets out a personal perspective on the nature of the work of such bodies and does not represent the views of those groups, nor the bodies that sponsored them.

2. This article considers briefly the role of scientific expertise; for analysis of expertise in moral philosophy and its proper contribution, see Archard D. Why moral philosophers are not and should not be moral experts. Bioethics 2011;25(3):119-27.

3. Organ Donation Taskforce (ODT). The potential impact of an opt-out system for organ donation in the UK. An independent report from the Organ Donation Taskforce. London: Department of Health; 2008. For the relevant documents, see http:/ /www.dh.gov.uk/en/Publicationsandstatistics/ Publications/PublicationsPolicyAndGuidance/DH_090312 (last accessed 7 Sep 2012).

4. See note 3, ODT 2008, 35.

5. See note 3, ODT 2008, annex I. 


\section{Jonathan Montgomery}

6. See note 3, ODT 2008.

7. For the report on this engagement, see note 3, ODT 2008, annex J. For other stakeholder correspondence, see annexes $\mathrm{K}$ and $\mathrm{L}$.

8. See note 3, ODT 2008, annex D.

9. Hansard HC. 17 Nov 2008, vol. 483, col. 5WS.

10. Dirty hands . . . the human cost: 2006 annual report of the chief medical officer on the state of public health. London: Department of Health; 2007, at chap. 4.

11. Sometimes minutes are available that enable this process to be traced, for example, see the Committee on Ethical Aspects of Pandemic Influenza minutes, archived at http:/ /webarchive.nationalarchives. gov.uk/+/www.dh.gov.uk/en/Publichealth/Flu/PandemicFlu/DH_065163 (last accessed 7 Sep 2012).

12. Report of the Committee of Inquiry into Human Fertilisation and Embryology. London: HMSO; 1984, at Cmnd 9314, para 11.22. This recommendation was subsequently accepted by Parliament on a vote on alternative versions of $\mathrm{cl} 11$ of the bill, which became the Human Fertilisation and Embryology Act 1990.

13. Smeaton v. Secretary of State for Health [2002] EWHC 610 (Admin).

14. For an account of these issues, see Warnock M. Nature and Mortality: Recollections of a Philosopher in Public Life. London: Continuum; 2003, at 94-101.

15. The tensions that arise from indeterminacy in this field can be seen to be played out in the debates over the need for precision in prosecution policy around assisted suicide following the decision of the House of Lords in R (Purdy) v. DPP [2009] UKHL 45, see further Montgomery J. Guarding the gates of St Peter: Life, death and law making. Legal Studies 2011;31(4): 644-66.

16. See note 14, Warnock 2003, at 99-100.

17. For example, Beauchamp T, Childress J. Principles of Biomedical Ethics. 6th ed. New York: Oxford University Press; 2008.

18. Nuffield Council on Bioethics (NCB). Public health: Ethical issues. London: Nuffield Council on Bioethics; 2007. This was the report of a working party chaired by Lord Krebs, of which the author was a member.

19. See also Montgomery J. The legitimacy of medical law. In: Maclean S, ed. First Do No Harm: Law Ethics and Medicine. Aldershot: Ashgate; 2006, at 1-16.

20. Coggon J. Harmful rights-doing? The perceived problem of liberal paradigms and public health. Journal of Medical Ethics 2008;34:798-801, exploring Raz J. Ethics in the Public Domain. Oxford: Clarendon; 1994.

21. Mill JS. On Liberty. London: JM Dent; 1972 (originally 1859).

22. See, for example, Dawson AJ, Verweij M. The steward of the Millian state. Public Health Ethics 2008;1(3):1-3.

23. World Health Organization. World Health Report 2000. Geneva: WHO; 2000.

24. Jochelson K. Nanny or Steward? The Role of Government in Public Health. London: King's Fund; 2005.

25. Brown G. Organ donations help us make a difference. The Sunday Telegraph 2008 Jan 13.

26. Warner G. Gordon Brown wants to nationalise our bodies by enforced organ donation; available at http://blogs.telegraph.co.uk/news/geraldwarner/5721489/Gordon_Brown_wants_to_nationalise_ our_bodies_by_enforced_organ_donation (last accessed 11 Feb 2012).

27. Marrin M. Even in death our organs are not for the PM to snatch. Sunday Times 2008 Nov 16.

28. See note 18, NCB 2007, para. 4.33-4.35.

29. For more explicit discussion of this point, see note 18, NCB 2007, para. 3.3-3.12.

30. See note 18, NCB 2007, para. 4.13.

31. See note 18, NCB 2007, chap. 7.

32. The working party drew principally on McDonagh M, Whiting P, Bradley M, Cooper J, Chestnutt I, et al. A Systematic Review of Public Water Fluoridation. York: NHS Centre for Reviews and Dissemination; 2000.

33. $R$ (Milner) v. South Central SHA [2011] EWHC 218 (Admin). It should be noted that the author chairs NHS Hampshire, which supported the fluoridation scheme, although the formal responsibilities for assessing the views expressed by the public lay with the Strategic Health Authority, NHS South Central.

34. Water Industry Act 1991, s 87; Water Fluoridation (Consultation) (England) Regulations 2005, SI 2005 No. 921.

35. See note 33, $R$ (Milner) v. South Carolina SHA [2011]. 
36. This engagement led to very rich data, and the quantitative material discussed here is only a small part of it-see note 3, ODT 2008, annex J.

37. See note 3, ODT 2008, fig. 2 on p. 26.

38. See note 3, ODT 2008, para. 12.5 and 12.9.

39. http://www.dignityindying.org.uk/research/opinion.html (last accessed 7 Sep 2012), citing McAndrew S. Religious faith and contemporary attitudes. In: A Park, Curtice J, Thomson K, Phillips M, Clery E, Butt S, eds. British Social Attitudes: 2009-2010. The 26th Report. London: Sage; 2010, at 87-113.

40. http:/ / www.carenotkilling.org.uk/?show $=441$ (last accessed 7 Sep 2012).

41. See note 2, Archard 2011.

42. See note 3, ODT 2008, para. 6.8 .

43. See note 3, ODT 2008, para. 11.1-11.5.

44. See note 3, ODT 2008, annex I. 